\title{
O AUTISMO E OS PROCESSOS PEDAGÓGICOS
}

\section{ARTIGO DE REVISÃO}

ALCANTARA, Elissandra Barreto de Oliveira de ${ }^{1}$

ALCANTARA, Elissandra Barreto de Oliveira de. 0 autismo e os processos pedagógicos. Revista Científica Multidisciplinar Núcleo do Conhecimento. Ano 05, Ed. 04, Vol. 06, pp. 121-133. Abril de 2020. ISSN: 2448-0959, Link de acesso: https://www.nucleodoconhecimento.com.br/educacao/processos-

pedagogicos

\section{RESUMO}

Entendido como uma desordem de cunho neurobiológico, o Autismo consiste em uma multiplicidade de prejuízos nas áreas de comunicação, interação social e padrões repetitivos de comportamentos e interesse. Trata-se de um distúrbio de desenvolvimento permanente e severamente incapacitante, isto é, não se tem comprovação cientifica para a sua cura. Também, o autismo pode vir associado a outras patologias e/ou condições clínicas. Existem características marcantes entre as crianças com autismo, essas individualidades demonstram-se essenciais em três aspectos, onde se destacam relações sociais, ocasião em que a criança autista tem dificuldade em se relacionar. O objetivo é apresentar de maneira efetiva, embasamento para que o educador compreenda melhor o que é autismo e com isto tenha condições para criar no cotidiano das suas aulas melhores estratégias de inclusão do portador de autismo na escola regular. Para que se procedesse ao artigo proposto, a coleta de dados foi composta por pesquisas em literaturas dispostas nas bases de dados da Internet, como Revistas Eletrônicas, Periódicos da CAPES,

\footnotetext{
${ }^{1}$ Bacharelado e Licenciatura em Enfermagem. Estudante do Programa PROFOP - R2 - Pedagogia (Formação Pedagógica em Pedagogia) Pela faculdade IBRA. Estudante do Curso de Psicopedagogia Clínica, Institucional e Educação Especial - Pela Faculdade Dom Alberto.
} 
MEDLINE, LILACS, SciELO, Biblioteca Virtual em Saúde (BVS); E-books, além de pesquisa em livros próprios. Conclui-se, portanto, que o planejamento para atender a criança com autismo precisa ser estruturado conforme ela se desenvolve, neste viés, é possível promover uma transformação na representação social sobre a criança com autismo. Assim, é preciso também, levar em conta ainda a função social da escola, pois, esta deve oportunizar cada vez mais experiências pedagógicas que aumentem a inclusão, buscando meios para receber crianças autistas.

Palavras-Chave: Autismo, processo pedagógico, educação.

\section{INTRODUÇÃO}

Sabe-se que o Transtorno do Espectro Autista - TEA, trata-se de um conjunto de distúrbios no desenvolvimento neurológico, e tem início precoce, comprometendo as habilidades comunicativas e sociais, afetando também o comportamento. Trazendo traços estereotipados. É, contudo, uma desordem neurobiológica, com múltiplos prejuízos, principalmente de interação social, que por vezes apresenta distúrbios permanentes e severamente incapacitantes, isto é, não se tem comprovação cientifica para a sua cura.

Contudo, não há exame complementar que possa comprovar se uma criança tem autismo. O diagnóstico de autismo em linhas gerais encontra-se baseado apenas em dados clínicos que envolvem a história e observação do comportamento. Determinados indivíduos com autismo possuem desenvolturas incomuns. Talvez por altercações em conexões cerebrais, ou mesmo por parte de prioridades préestabelecidas pelo próprio cérebro em seu processamento de aspectos e informações e mais importantes.

Assim sendo, percebe-se a importância em se trabalhar este tema em conjunto com as diretrizes tanto teóricas quanto práticas direcionadas de modo especial aos educadores, para que estes possam desenvolver suas práxis pedagógicas voltadas para a devida inclusão das crianças que são acometidas por esse distúrbio. 
Neste enlace, o objetivo deste artigo é apresentar de maneira efetiva, embasamento para que o educador compreenda melhor o que é autismo e com isto tenha condições para criar no cotidiano das suas aulas melhores estratégias de inclusão do portador de autismo na escola regular.

Trata-se, portanto, de pesquisa bibliográfica, onde foram feitas pesquisas em literaturas dispostas nas bases de dados da Internet, como Revistas Eletrônicas, Periódicos da CAPES, MEDLINE, LILACS, SciELO, Biblioteca Virtual em Saúde (BVS); E-books, além de pesquisa em livros próprios.

Diante da proposta inserida, o alvo aqui não é esgotar esboços acerca de conceitos em autismo e sim aflorar no profissional que trabalha com educação, a existência de muitos meios de se trabalhar o cognitivo das crianças portadoras de autismo.

\section{FALANDO SOBRE AUTISMO}

É correto afirmar que o número de crianças que são diagnosticadas com a síndrome do autismo acendeu admiravelmente. Contudo, além disso, têm pais, que pela ausência de conhecimento, adiam a procura por profissionais especializados que podem prestar ajuda em concretizar este diagnóstico. Fazendo com que a criança passe a ser afetada negativamente durante sua vida escolar (BEYER, 2006).

Ao buscar a biografia do autismo, é possível encontrar diversos pesquisadores importantes que se debruçaram a compreender essa síndrome. Importante definir o que vem a ser síndrome, o Dicionário Houaiss (2001, p. 634), traz a seguinte definição: "agregado ou conjunto de sinais e sintomas associados a alguns processos mórbido/doentios que, juntos constituem um quadro de enfermidade ou doenças". Por esta definição, pode-se dizer que uma síndrome não necessariamente caracteriza uma doença, mas um grupo de doenças.

O termo autismo foi introduzido na psiquiatria pela primeira vez por Plouller, médico psiquiatra, no ano de 1906 para descrever o sinal clínico de isolamento e para encenar pela repetição do auto referência de alguns casos. E em 1911, o então psiquiatra 
Eugen Bleuler, empregou o mesmo adjetivo, não para designar o distúrbio do desenvolvimento humano, e sim para pacientes esquizofrênicos que tinham a tendência de se isolar (SALLE et al., 2005).

Existem características marcantes entre as crianças com autismo, essas individualidades demonstram-se essenciais em três aspectos, onde se destacam relações sociais, ocasião em que a criança autista tem dificuldade em se relacionar. A linguagem e comunicação, pois, a linguagem das crianças autistas é demasiadamente estranha, uma vez que estas não usam a linguagem como a maioria das pessoas usa e ainda alta de aceitação das mudanças, momento onde há uma manifestação de persistência em não variar o ambiente, demonstrando-se inflexível e rígida para aderir a novas rotinas (ALBUQUERQUE et al., 2009).

No entendimento de autismo, implica dizer que existem crianças que conseguem se comunicar através de frases e outras não. Tem crianças que desenvolvem a leitura sozinha muito cedo e outras jamais conseguirão se alfabetizar. Existem crianças que apresentam retardo mental associado e outras com inteligência normal ou acima do normal. Existem àquelas que desenvolvem o sistema motor normalmente e outras que só vai conseguir andar muito tarde. Há também crianças com diferentes doenças associadas a outras sem qualquer patologia concomitante. Ainda assim, todas essas crianças serão classificadas como autistas embora suas características sejam diferentes (GIKOVATE, 2009).

Ademais, existem distintas definições e critérios diagnósticos do que vem a ser o autismo, assim, não é tarefa fácil traçar um paralelo de incidência que seja confiável tendo em vista estes inúmeros diagnósticos, pois de acordo com as definições, aumenta ou diminuem a quantidade de crianças diagnosticadas. Sabe-se que grande parte dos sintomas são percebidos logo nos primeiros anos de vida da criança, com alternância em sua intensidade, partindo do mais brando ao mais severo (MELLO, 2013). 
É admirável observar que as características cognitivas de cada criança portadora de autismo, traz o elo com a sua faixa etária, presença ou não de retardo mental e mesmo o grau do autismo (ORRÚ, 2009).

\section{O PROCESSO DE APRENDIZAGEM DA CRIANÇA AUTISTA}

Muitos educadores sentem-se em situações desafiadoras diante do autismo no que se refere o processo de ensino e aprendizagem. Inicialmente, é importante dizer que cada aluno autista possui suas particularidades, visto que as manifestações desse transtorno alteram imensamente, tanto no que tange ao nível de desenvolvimento quanto em relação à idade (BELISÁRIO FILHO; CUNHA, 2010).

Logo, a fim de compreender melhor as peculiaridades de uma pessoa autista, se faz necessário prestar atenção aos seguintes critérios, como, dificuldade na ação comunicativa quando acompanhada ao desenvolvimento neuropsicomotor; comprometimento em suas relações sociais, como ainda dificuldade na troca de olhar mesmo com pessoas da família além da apresentação de estereotipias motoras, como por exemplo, balancear os braços, frente a situações diferentes de sentimentos, também fala estereotipada e (BELISÁRIO FILHO; CUNHA, 2010).

Sabe-se que as crianças autistas têm dificuldades de interagir socialmente, o que acarreta prejuízos em seu comportamento, sobretudo por realizar movimentos corporais estereotipados, as crianças autistas também podem exibir empenho insistente em apenas partes de objetos e sobretudo, movimentos, como o de rodinhas, as hélices de ventiladores, entre outras coisas. Diferenciam-se por hábitos que se repetem no dia a dia, com forte aversão a mudanças (CAMPOS, 2008).

O emblema rotina é imensamente comum em crianças com autismo, por isso quando iniciam a vida escolar padecem com este novo ambiente escolar, não apenas pelo ambiente diferente daquele com o qual está acostumado, mas até pela presença de outras crianças que interagem entre si através de brincadeiras. $O$ ingresso na escola, desse modo, denota, também, mudança na rotina, isso acaba provocando uma desorganização nesta criança (CAMARGOS, 2005). 
Nesta perspectiva, programas de estimulação dos processos de interação comunicativa entre as crianças em contextos de integração devem ser instituídos por meio da aplicação de uma análise ecológica para a avaliação e intervenção no desenvolvimento e para a implementação de estratégias que fomentam a interação entre crianças com problemas e sem problemas (LOPES, 2008).

Igualmente, é importante destacar que as primeiras experiências da criança autista junto ao ambiente escolar, seja feita com a presença das pessoas de seu convívio habitual, em seu viver cotidiano. Cabe, portanto, à escola criar rotinas de estudo, distintas daquelas que o aluno possa ter em casa. No que se refere à prática educacional, a forma de apresentar o mundo para a criança autista se processa de maneira diferenciada (GENTIL; NAMIUTI, 2015).

Muitas ações podem contribuir para o processo de ensino e aprendizagem da criança autista, conforme preconizado pelo Pacto Nacional pela Alfabetização na Idade Certa da Educação Inclusiva (PNAIC), onde, o processo de aprendizado deve ser efetivado a partir de reais condições que valorizem a singularidade de cada criança, constituindo a organização de rotinas para com a criança autista, para lhe proporcionar atividades em grupos. Sempre se dirigir de forma verbal ao aluno autista durante as atividades frente à sua necessidade. Logo, planejar formas de avaliação que considere as disparidades da sala de aula, e não uma estimativa pautada na semelhança (BRASIL, 2014).

Assim, torna-se muito importante ter conhecimento das características de autismo em geral e do educando em particular. Conhecer o seu estilo de aprendizagem, preferências, necessidades e pontos fortes. Ter esses conhecimentos a respeito do aluno autista será útil para compreender as implicações especiais em qualquer um dos ambientes escolares (LOPES, 2008).

Porquanto, não se deve desconsiderar que, caso o aluno autista precise de apoio educacional especializado, é fundamental a sua frequência no Atendimento Educacional Especializado (AEE), para complementar sua escolaridade, visto que o trabalho com uso práticas pedagógicas que venham somar ao seu desenvolvimento 
sócio cognitivo, esta ação deve ser realizado não somente pelo professor da sala de aula comum como também deve ser incentivada aos professores do AEE (BRUNI, 2013).

\section{FORMAÇÃO DOCENTE E O ALUNO AUTISTA}

Ao analisar a proposta da formação do professor como ponto essencial perante do método inclusivo, busca-se uma grande mudança na atmosfera educacional, porquanto permitirá ao educador um novo olhar diante da variedade que compõe a totalidade escolar, com um entendimento inovador em sua arte pedagógica, colaborando para um ambiente mais inclusivo, garantindo uma formação mais humanizada aos seus educandos. Pois, conforme a LDB 9394/96 em seu artigo 59, inciso III é afiançado ao aluno com necessidades especiais educadores com adequada especialização em nível médio ou superior, para prestar acolhimento especializado, assim também professores do ensino regular que estejam habilitados para a integração destes alunos nas salas de aula comuns (BRASIL 1996).

Ao que concerne à educação inclusiva, a educação especial faz parte da proposta pedagógica da escola comum, na qual promove 0 atendimento às necessidades específicas dos alunos. Destarte, o Atendimento Educacional Especializado (AEE) deve estar inserido no Projeto Político Pedagógico (PPP) da escola, e caso não esteja, a situação legal da escola não se encontra totalmente regular, para tanto é preciso adequá-la, conforme as normas federais, estaduais e municipais (MENEZES, 2013).

É importante destacar que o AEE se trata de uma unidade com o papel de apoio pedagógico que venha complementar a escolarização deste grupo de alunos, logo, as atividades por ele desenvolvidas precisam ser diferentes daquelas que são realizadas na sala de aula. Este não deve ser entendido como mero reforço escolar ou ainda para realizar tarefas de casa. $O$ atendimento prestado nesse contexto, não substitui a escolarização, ou seja, o aluno precisa estar devidamente matriculado em andamento normal do ensino regular - seu acompanhamento será em turno inverso (BRASIL, 2014). 
É, portanto, nesse contexto escolar que se deve enfatizar a importância do Pedagogo e das organizações educacionais na educação de crianças com síndrome de autismo em escolas de ensino regular, o que tem sido feito, para preparar o pedagogo/professor, e a sua valorização dada a este trabalho, para assegurar qualidade e a eficácia na aprendizagem do aluno, em que se deve levar em conta o nível de desenvolvimento global da aprendizagem do autista que, não raro, é lenta e gradativa (MILAGRE; SOUZA, 2011).

Para Farias (2008), é preciso que sejam empregadas algumas estratégias que se relacionem com os interesses específicos do aluno, bem como suas habilidades, dando espaço aquilo que mais acentua sua atenção, como por exemplo, mapas e trens. Os recursos visuais devem ser ofertados paralelamente aos estímulos auditivos, pois, torna-se útil para promover a compreensão o aluno em situação de TGD, como figuras, fotos e até mesmo a escrita.

Frente à escrita, alguns alunos tendem a exibir dificuldades em sua coordenação motora, necessitando assim, de apoio suplementar, como o acompanhamento durante as aulas, como, por exemplo, aconselhar e monitorar o emprego de gravador para que se registre as aulas, computador para facilitar o acompanhamento ou mesmo disponibilizar os conteúdos que serão abordados por meio de versão escrita (ALVES, 2005).

É pertinente dizer que há sim, a falta de conhecimento, ainda por parte dos professores envolvendo essas concepções e conceitos têm implicações diretas no trabalho pedagógico cotidiano, pois sem a devida formação, os profissionais sentemse despreparados para receber em sua turma alunos com necessidades especiais. Semelhante preocupação reporta-se à formação dos profissionais que operam na gestão e coordenação, que deveriam estar inteirados e capacitados para trabalhar com essa realidade, mesmo porque a eles cabe organizar, preparar e estruturar o currículo escolar, além de orientar os aos professores (FARIAS, 2008).

Falta ao Professor refletir sobre o seu próprio processo de pensamento, como também, do pensamento de seu aprendiz e o momento específico da aprendizagem. 
Apenas nesse sentido, o professor se preparará na construção de uma prática pedagógica adequada à diversidade em classe (ROPOLI, 2010).

Sendo assim, nada mais justo que se deve reforçar eticamente que todos os profissionais de educação precisam refletir os conceitos de afeto, motivação e conflito, rejeitando a uma teoria generalista de aprendizagem, de tal sorte que possa definir com eficácia o que é verdade, e ajudar a regulação de emoção e exploração no desenvolvimento global de qualquer criança, tendo como base os equilíbrios fundamentais da criança e sua família (SILVA, 2014).

As políticas públicas destinadas à Educação Inclusiva, conforme Silva (2014), apontam suas ações visando o atendimento de questões peculiares, mas é de suma importância que os professores compreendam que os artifícios necessários perante a arte de ensinar e aprender, mormente com estes alunos especiais - não é somente dever dos educadores atuantes no AEE. O planejamento também deve ser feito pelo professor do ensino regular, levando em consideração os direitos de aprendizagem de cada aluno, de forma a realizar um trabalho em harmonia com seus colegas que atuam junto ao $\mathrm{AEE}$, ou seja, esta deve ser uma proposta de trabalho envolvendo toda escola e seus componentes (JOSÉ; COELHO, 2008).

\section{POLÍTICAS PÚBLICAS EDUCACIONAIS PARA OS AUTISTAS}

A Educação Inclusiva, tem sido positivada por várias normas, mas pode-se dizer que ela encontra seu respaldo legal na Constituição Federal de 1988 (CF/88), a qual estabelece a prioridade na igualdade de condições, seja está para o ingresso e permanência na escola, de forma unificada. Esta traz também o elenco da oferta de atendimento educacional de forma especializada, principalmente no ensino regular artigo 208/ inciso III (BRASIL, 2009).

O combate à discriminação e toda forma de preconceito é fortemente ratificado em algumas leis, sendo que se pode destacar: o Estatuto da Criança e do Adolescente ECA; Declaração de Salamanca de 1994, que versa acerca dos Princípios, Políticas e Práticas na Área das Necessidades Educativas Especiais; o Decreto Federal №. 
3956/2001 que promulgou a Convenção Interamericana para a abolição de todas as formas de discriminação contra as pessoas com eficiência; a Lei №. 3298 de 20 de dezembro de 1999 que dispõe sobre a Política Nacional para a Integração da Pessoa Portadora de Deficiência; e o Decreto Federal №. 6949/2009, que promulgou a Convenção Internacional sobre os direitos de pessoas portadoras de deficiência (BRASIL, 2006).

No âmbito da educação destaca-se a Lei Federal de Diretrizes e Bases da Educação № 9.394/1996 (LDB) e a Resolução CNE/CEB №. 02/2001, que institui Diretrizes Nacionais para a Educação Especial na Educação Básica, ambas tratam acerca do trabalho através de um currículo diferenciado e flexível que atenda os alunos da Educação Especial, inclusive a LDB/96, define no Art. 59 (Incisos I - III) que:

Art. 59. Os sistemas de ensino assegurarão aos educandos com necessidades especiais:

I - currículos, métodos, técnicas, recursos educativos e organização específica, para atender às suas necessidades;

III - professores com especialização adequada em nível médio ou superior, para atendimento especializado, bem como professores do ensino regular, capacitado para a integração desses educandos nas classes comuns (BRASIL, 1996).

Desse modo, a escola pode ser percebida como um espaço de desenvolvimento de competências para crianças com autismo, mas ainda se compõe um grande desafio em face aos professores, visto que nem todas as crianças com autismo irão se adaptar ao ensino regular. Determinados alunos, autistas, exibem distintas necessidades, vindo a se integrar melhor em escolas especiais. Logo, conforme o comprometimento individual, deveras, há sobretudo, algumas necessidades a serem supridas não só pelo corpo pedagógico, mas em concomitância com equipe multiprofissional diante de cada caso. 
As mudanças são evidenciadas com novas ordens legais, onde tem-se: a majestosa Lei ํo. 12.764 do ano de 2012, a qual constitui a Política Nacional de Proteção dos Direitos da Pessoa com Transtorno do Espectro Autista. Esta lei versa sobre os princípios que atendem a Política Nacional de Educação Especial frente a perspectiva da educação inclusiva, onde, não distante, traz à luz a finalidade da Convenção sobre os Direitos das Pessoas com Deficiência (CRUZ, 2009).

Frente ao exposto, o mérito de que a aludida Política Nacional de Educação, ainda de 2008, não pode ser menor, onde, dadas mudanças estruturais e ainda conceituais no aparelhamento da norma educacional foram pela mesma formadas. Passou-se então a preceder $\mathrm{o}$ atendimento educacional especializado, tendo este o objetivo maior de identificar, organizar e elaborar planos por meio de recursos pedagógicos capazes de viabilizar a acessibilidade. Eliminando barreiras para a integral participação daqueles alunos que necessitam (VIANNA; SILVA, 2014).

\section{CONSIDERAÇÕES FINAIS}

A ideia em se discutir o autismo dentro das possibilidades pedagógicas ocorre no sentido de ter em mente que para atuar na educação especial - no caso em tela, o aluno com autismo, o educador deverá tomar como base a magnitude de sua formação, a jornada acadêmica inicial e ainda de forma continuada, buscando conhecimentos e adequações para a efetivação do magistério, sobretudo, ao considerar a realidade de se trabalhar com a necessidade especial do aluno.

Muitas são as dúvidas que acompanham a educação da criança com autismo, contudo, é preciso se sentir confiante frente sua prática pedagógica, fazendo com que este aluno seja tratado da melhor forma possível, em sala de aula, sem diferenças. Ademais, o planejamento é essencial, e modelos de atividades fazem toda a diferença, respeitando os limites da criança, encorajando e impondo limites.

Como dito, não deve haver diferenças, e sim ser tratado da mesma maneira como são tratadas as outras crianças, com respeito e atenção às suas necessidades. Onde, uma rotina deve ser estabelecida, evitando mudanças inesperadas. Ao se trabalhar com a 
educação de uma criança com autismo, é preciso primeiramente identificar o motivo de maior no aluno com autismo. Por exemplo, se o mesmo não está confortável com um brinquedo, deve ser encorajado a escolher outro;

O trabalho com crianças autistas, demanda de muito envolvimento, carinho e atenção. Para que o êxito seja alcançado no âmbito do desenvolvimento dos alunos com transtorno do autismo, é imperativo entender a diversidade de ações que se encontram envoltos no processo de ensino e aprendizagem para essa clientela. É, portanto, imprescindível que o professor especializado nesse processo busque na literatura científica o apoio teórico e paralelamente compartilhe as experiências, apoio e conselhos práticos junto a outros professores que tenham ou não alunos autistas e outras necessidades educacionais especiais.

Com base no estudo proposto, verifica-se que o planejamento para atender a criança com autismo precisa ser estruturado conforme ela se desenvolve. Por exemplo, ao trabalhar com crianças pequenas as prioridades devem ser a fala, a interação social, a linguagem e a educação, dentre outros, que podem ser apreciados como instrumentos essenciais na promoção da inclusão da criança com autismo. Neste viés, é possível promover uma transformação na representação social sobre a criança com autismo, sendo fundamental que a instituição que atende o autismo, a escola e o professor fundamentem a sua prática na medida em que compreendam os distintos aspectos relacionados a este tipo de transtorno, além de suas peculiaridades e as consequências para o seu desenvolvimento.

É preciso levar em conta ainda a função social da escola, esta deve oportunizar cada vez mais experiências pedagógicas que aumentem a inclusão. A escola deve sempre ser inclusiva e isso implica em ofertar de forma igual as oportunidades, não somente de ensinar como também trabalhar a participação na vida social de crianças com autismo, para isso o conjunto de dados deve ser adequado segundo as necessidades de cada aluno. Vale ressaltar também que não é da criança o dever de se adaptar a escola, mas sim a própria escola deve buscar meios para recebê-la. 


\section{REFERÊNCIAS}

ALBUQUERQUE, C. A., CRUZ, C.S., RUTHES, B.L., MOSQUERA, C.F.F. Panorama Geral Sobre o Transtorno Autístico. Revista O Mosaico, FAP/PR, n.1, 2009

ALVES, Fátima. Inclusão: muitos olhares vários caminhos, e um grande desafio. Rio de Janeiro: Wak Editora, 2005

BELISÁRIO FILHO, José Ferreira; CUNHA, Patrícia. A Educação Especial na Perspectiva da Inclusão Escolar: transtornos globais do desenvolvimento. Brasília: Ministério da Educação, Secretaria de Educação Especial; [Fortaleza]: Universidade Federal do Ceará, 2010.

BEYER, H. O. Da Integração escolar à Educação Inclusiva: Implicações Pedagógicas. In: BAPTISTA, C. R. (Org.) Inclusão e Escolarização: múltiplas perspectivas. Porto Alegre: Mediação, 2006. p. 73-81.

BRASIL. Presidência da República. Lei no 9.394, de 20 de dezembro de 1996. Estabelece as diretrizes e bases da educação nacional. Brasília - DF, 1996

BRASIL. Mistério da Educação. Direito à educação: subsídios para a gestão dos sistemas educacionais - orientações gerais e marcos legais. Brasília: MEC. SEESP, 2006.

BRASIL. Constituição da República Federativa do Brasil. Brasília: Senado Federal, 2009.

BRASIL. Secretaria de Educação Básica. Diretoria de Apoio à Gestão Educacional. Pacto Nacional pela Alfabetização na Idade Certa: Educação Inclusiva / Ministério da Educação, Secretaria de Educação Básica, Diretoria de Apoio à Gestão Educacional. - Brasília: MEC, SEB, 2014.

BRUNI, Ana Rita [et al.] Autismo \& Realidade Cartilha, Autismo e Educação. São Paulo, 2013. 
CAMARGOS Jr., Walter [et al.]. Transtornos invasivos do desenvolvimento: $3^{\circ}$ Milênio. Brasília: CORDE, 2005. 260 p. Disponível em: <www.fcee.sc.gov.br/>.

CAMPOS, A.M.C. Observando a conexão afetiva em crianças autistas. Rio de Janeiro: Puc-Rio, 2008.

CRUZ, Álvaro Ricardo de Souza. O direito à diferença. Belo Horizonte: Arraes Editores, 2009.

FARIAS, lara M.; MARANHÃO, Renata V. A.; CUNHA, Ana C. B. Interação professoraluno com autismo no contexto. Revista Brasileira de Educação Especial. Marília SP, v. 14, n. 3, p. 365-384, 2008.

GENTIL, Késia Priscila Gomes; NAMIUTI, Aline Pavan Sarilho. Autismo na educação infantil. Revista Brasileira Multidisciplinar, v. 18, n. 2, 2015

GIKOVATE, Carla G. Autismo: compreendendo para melhor incluir. Rio de Janeiro, 2009.

Disponível

em:

http://www.carlagikovate.com.br/aulas/autismo\%20compreendendo\%20para\%20mel hor\%20incluir.pdf

HOUAISS, Antônio. Dicionário Houaiss da Língua Portuguesa. Rio de Janeiro, Ed. Objetiva, 2001.

JOSÉ, Elizabete A; COELHO, Maria T. C. Problemas de Aprendizagem: Série Educação. 12. ed. São Paulo: Ática, 2008.

LOPES, Eliana R. B. Autismo: trabalhando com a criança e com a família. $3^{a}$ ed. São Paulo: EDICON: AUMA, 2008.

MELLO, Ana Maria S. [et al]. Retratos do autismo no Brasil. São Paulo: Impressão: Gráfica da AMA - Associação de Amigos do Autista, doada pela Fundação Ellijas Gliksmanis, 2013. 
MENEZES, Adriana. R. S. A inclusão de alunos com autismo em escolas públicas de Angra dos Reis. 2013. Disponível em: <http://www.eduinclusivapesquerj.pro.br/images/pdf/A_INCLUSAO_DE_ALUNOS_COM_AUTISMO_EM_ESCOLA S_PUBLICAS_DE_ANGRA_DOS_REIS.pdf>

MILAGRE, Marilene De Oliveira; SOUZA, Wagna Da Silva. Um estudo da integração do autista no ensino regular. Serra, 2011.

ORRÚ, Sílvia Ester. Autismo, linguagem e educação: interação social no cotidiano escolar. 2. ed. Rio de Janeiro: Wak, 2009.

ROPOLI, E. A. [et al]. A educação especial na perspectiva da inclusão escolar: a escola comum inclusiva. Brasília: MEC/SEESP, 2010.

SALLE, Emílio. Autismo infantil - sinais e sintomas. In: CAMARGOS Jr., Walter [et al.]. Transtornos invasivos do desenvolvimento: 3ํMilênio. Brasília: CORDE, 2005. 260 p. Disponível em www.fcee.sc.gov.br/

SILVA, Rosane A. F. Os direitos e a aprendizagem. In: BRASIL. Secretaria de Educação Básica. Diretoria de Apoio à Gestão Educacional. Pacto Nacional pela Alfabetização na Idade Certa: Educação Inclusiva / Ministério da Educação, Secretaria de Educação Básica, Diretoria de Apoio à Gestão Educacional. Brasília: MEC, SEB, 2014.

VIANNA, Carlos R.; SILVA, Rosane A. F. Uma ilha de inclusão no mar de exclusão? In: BRASIL. Secretaria de Educação Básica. Diretoria de Apoio à Gestão Educacional. Pacto Nacional pela Alfabetização na Idade Certa: Educação Inclusiva / Ministério da Educação, Secretaria de Educação Básica, Diretoria de Apoio à Gestão Educacional. Brasília: MEC, SEB, 2014.

Enviado: Março, 2020.

Aprovado: Abril, 2020. 